\title{
Shaped Places of Carroll County New Hampshire
}

\author{
CYRUS PENARROYO
}

University of Michigan

Shaped Places of Carroll County New Hampshire speculates on the complex reciprocity between who we are and the shape of where we live; between identities and the built environments that support them. Culminating in the design of three linear cities, the project seeks to geometrically organize population at a geographic scale to carefully prescribed ends - drawing upon a seemingly unlikely set of protagonists and sources from Frank Stella to M.A. Ochitovic, and from American formalism to critical geography. Forced to co-exist, this melange informs strategies for co-existence; for patterns of urbanization that urbanize the rural while ruralizing the urban.

A notorious swing state, New Hampshire remained purple on the U.S. presidential election map until late on November 8,2016 . Several factors underlie the state's indefinite political leanings. New Hampshire is a microcosm of the political divide between liberal urban and conservative rural populations that increasingly characterizes the United States as a whole, and the state has been gerrymandered to the benefit of conservative politicians. The latter action profoundly impacts the political reality of the state through the figuring of invented geographic shapes. Shape and content forge a complex reciprocity.

\section{IRREGULAR POLYGONS}

In his 1966 essay, "Shape as Form: Frank Stella's Irregular Polygons," Michael Fried applauded Stella for a very precise quality. Each painting in the Irregular Polygons featured a shaped canvas containing geometric bands of color within. Fried noted that it was impossible to determine whether the geometry of the stripes dictated the shape of the canvas or vise-versa. For Fried the mutual dependence between colored bands and canvas support prohibited all meaning external to the form, securing the status of high art. Shape and content forged a complex reciprocity.

\section{CENSUS PLACES}

Each painting within Stella's "Irregular Polygons" is named after a town in Carroll County, New Hampshire. Many of these towns are also Census Places. The shapes of Census Places are rarely defined by sensible markers or physical features. Rather, it is the instrumentalization of policy and control of population within the Census Place that makes its shape real. Shape and content forge a complex reciprocity.

\author{
MCLAIN CLUTTER \\ University of Michigan
}

\section{LINEAR CITIES}

Shaped Places recalls the visions of Russian Constructivism in which the linear city was a tool to unite urban and rural populations. These unbuilt examples deployed repeating planning units along infrastructural lines composing housing, production, institutions, nature, and collective space. Rural and urban populations were meant to merge as one public for the Revolutionary State.

Shaped Places has three sites, each a Census Place Sanbornville, Union, and Conway. In each site, the formal logic from a Stella canvas is applied to the shape of the eponymous census place to yield zoning bands. Along these bands, linear city planning modules would be deployed, contorting to the shape of their geographic host to elide rural and urban populations. Within, each inhabitant would find herself perpetually confronted with the other, perpetually usurped within the body politic, by design. Shape and content forge a complex reciprocity. 


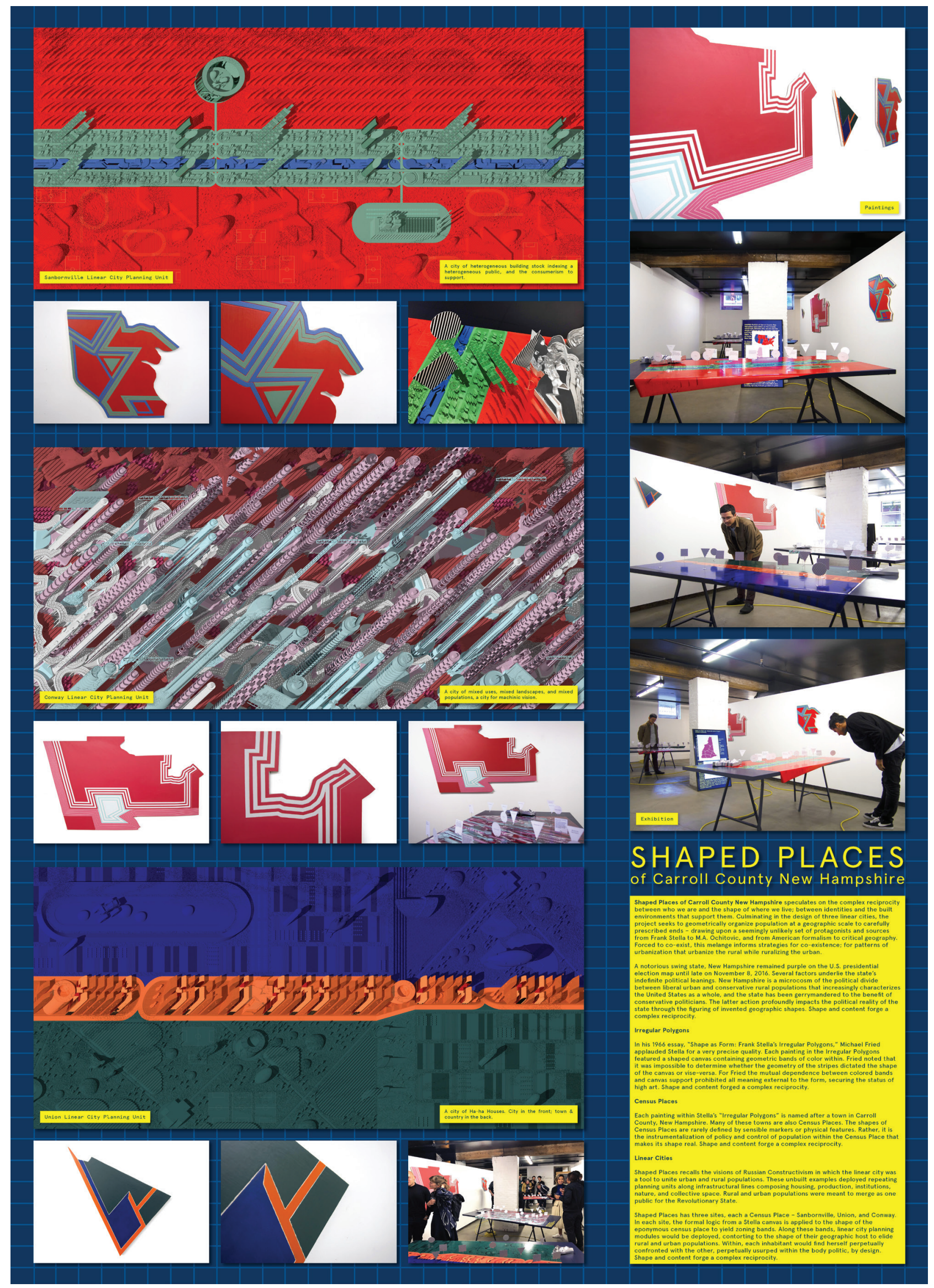

